Research Paper

\title{
Exosomes from Macrophages Exposed to Apoptotic Breast Cancer Cells Promote Breast Cancer Proliferation and Metastasis
}

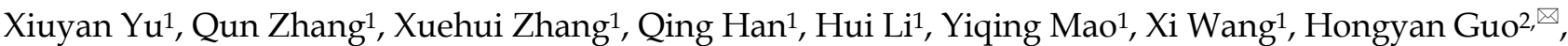 \\ David M. Irwin ${ }^{3,}$, Gang Niu ${ }^{4,}$ and Huanran Tan ${ }^{1,}$
}

1. Department of Pharmacology, School of Basic Medical Sciences, Health Science Center, Peking University, Beijing 100191, China

2. Department of Gynaecology and Obstetrics, Peking University Third Hospital, Beijing 100191, China

3. Department of Laboratory Medicine and Pathobiology, University of Toronto, Toronto, ON M5S 1A8, Canada

4. Beijing N\&N Genetech Company, Beijing 100082, China

$\square$ Corresponding authors: Prof. Huanran Tan, Department of Pharmacology Peking University, Health Science Center Physiology Building\#232, 38 Xue Yuan Road Beijing 100191, China. Tel: +86 10 82802004; Fax: +86 10 82802004; E-mail: tanlab@bjmu.edu.cn. Prof. David M. Irwin, Department of Laboratory Medicine and Pathobiology, University of Toronto, Toronto, Ontario M5S 1A8, Canada. Tel.: +1-416-978-0519; Fax: +1-416-978-5959 (D.M.I.); E-Mail: david.irwin@utoronto.ca. Mr Gang Niu, Beijing N\&N Genetech Company, Beijing, 100082, China. Tel.: +86-10-6404-7343 (G.N.); Fax: +86-10-6403-1254 (G.N.); E-Mail: nngene@sohu.com. Prof. Hongyan Guo, Department of Gynaecology and Obstetrics, Peking University Third Hospital, Beijing 100191, China. Tel./Fax: +86-10-82266699 (H.G.); E-Mail: bysyghy@163.com.

(C) Ivyspring International Publisher. This is an open access article distributed under the terms of the Creative Commons Attribution (CC BY-NC) license (https://creativecommons.org/licenses/by-nc/4.0/). See http://ivyspring.com/terms for full terms and conditions.

Received: 2018.11.05; Accepted: 2019.04.23; Published: 2019.06.02

\begin{abstract}
Exosomes have recently become the subject of increasing research interest. Interactions between tumor and host cells via exosomes play crucial roles in the initiation, progression and invasiveness of breast cancer. In our study, we used exosomes isolated from a co-culture model of THP-1-derived macrophages exposed to apoptotic MCF-7 or MDA-MB-231 breast cancer cell line cells to investigate their effects on naïve MCF-7 or MDA-MB-231 cells in vitro and in vivo. This post-chemotherapy tumor microenvironment model allowed us to explore possible mechanisms that explain increased proliferation and metastasis of breast cancer seen in some patients. Our results suggest that while exosomes derived from macrophages normally inhibit proliferation and metastasis of MCF-7 or MDA-MB-231 cells, exposure of macrophages to breast cancer cells that have experienced chemotherapy are modified them to promote these processes. Exosomes from macrophages exposed to apoptotic cancer cells have increased amounts of IL-6 that increases the phosphorylation of STAT3, which likely explains the increased transcription of STAT3 target genes such as CyclinD1, MMP2 and MMP9. These observations suggest that the inhibition of exosome secretion and STAT3 signaling pathway activation might suppress the growth and metastasis of malignant tumors, and provide new targets for therapeutic treatment of malignant tumors after chemotherapy.
\end{abstract}

Key words: exosome, apoptosis, metastasis, STAT3, breast cancer

\section{Introduction}

Breast cancer is one of the most lethal cancers affecting women worldwide and is estimated to account for $30 \%$ of all new cancer diagnoses in women [1]. This cancer has a poor prognosis, therefore, even with modern treatment methods, it claims the lives of almost half a million women each year [2]. The mechanisms of breast cancer expansion and progression have not been fully elucidated [3]. Exosomes, have been proposed to have a role in communications between tumor cells and their microenvironment and have been demonstrated to be involved in metastasis [4]. Exosomes are naturally produced, membrane vesicle-like structures that range in size from 30 and $100 \mathrm{~nm}$ [5]. Increasing evidence suggests that tumor cells release exosomes that influence tumor initiation, proliferation, progression, metastasis and drug resistance [6]. Studies have presented evidence that exosomes have 
numerous functions and are key for an array of biological events, including coagulation and intercellular signaling [7]. Exosomes, as mediators of cell-cell communication, potentially affect interactions between cells of the immune system and tumors [8] and it is possible that exosomes function as vectors for the intercellular transfer of signaling molecules, thus provide a mechanism for cell-to-cell communication and autologous amplification of cellular responses [9]. The contents of exosomes vary with their cellular and tissue origins, and include proteins, nuclear acids and lipids that are adapted to their functions [10].

Current research on the immuno-cellular effects on progress of tumors is mainly focused on the roles of cytokines [11], while little research has been conducted on the role of macrophage-derived exosomes in cancer recurrence and metastasis after chemotherapy [12]. Chemotherapy often leads to apoptosis of cancer cells, which potentially modifies the physiological state of macrophages and their release of exosomes [13]. To examine the role of macrophage-derived exosomes in the initiation and progression of metastasis after chemotherapy, we established a post-chemotherapy cancer microenvironment model using THP-1 derived macrophages co-cultured with apoptotic cells from the breast cancer cell line MCF-7 or MDA-MB-231. Our results suggest the possibility that after chemotherapy, exosomes derived from macrophages play a crucial role in promoting breast cancer proliferation and metastasis by activating the STAT3 signaling pathway.

\section{Methods}

\section{Cell culture}

THP-1 monocytes (ATCC ${ }^{\circledR}$ TIB-202 ${ }^{\mathrm{TM}}$ ) was cultured in RPMI1640, MCF-7 (ATCC ${ }^{\circledR}$ HTB-22 ${ }^{\mathrm{TM}}$ ) and MDA-MB-231 (ATCC ${ }^{\circledR}$ HTB-26 ${ }^{\mathrm{TM}}$ ) cells were cultured in DMEM high glucose medium (Life Technologies, USA), supplemented with $10 \%(\mathrm{v} / \mathrm{v})$ fetal bovine serum (FBS) (Biological Industries, USA) and maintained at $37^{\circ} \mathrm{C}$ in a humidified $5 \% \quad \mathrm{CO}_{2}$ atmosphere.

\section{Isolation of exosome from co-cultured macrophages with apoptotic MCF-7 cells}

THP-1 monocytes were seeded at $5 \times 10^{5} / \mathrm{ml}$ in a culture flask and stimulated to differentiate into macrophages with $200 \mathrm{nM}$ Phorbol 12-myristate 13-acetate (PMA) for $72 \mathrm{~h}$ [14, 15]. MCF-7 cells $(1 \times$ $10^{5} / \mathrm{mL}$ ) were treated for $12 \mathrm{~h}$ with $0.3 \mathrm{mM}$ hydrogen peroxide $\left(\mathrm{H}_{2} \mathrm{O}_{2}\right)$ or $25 \mu \mathrm{M}$ cisplatin to induce apoptosis [16, 17]. MDA-MB-231 cells $\left(1 \times 10^{5} / \mathrm{mL}\right)$ were also treated for $12 \mathrm{~h}$ with $0.3 \mathrm{mM} \mathrm{H}_{2} \mathrm{O}_{2}$. Cellular apoptosis was confirmed by flow cytometry, using Annexin V-FITC/Propidium iodide (PI) co-staining (Solarbio ${ }^{\circledR}$ Life Sciences, China) according to the instructions of the kit manufacturer using a FACSCalibur (Becton Dickinson, NJ, USA). Apoptotic MCF-7 or MDA-MB-231 cells were collected and co-cultured with THP-1 derived macrophages at a ratio of 1:2 for 3 days, and then the supernatants were collected for exosomes extraction, as previously described [13]. We defined exosomes derived from macrophages co-cultured with apoptotic MCF-7 cells as the Co-exo group, and exosomes from the macrophage alone as the Mac-exo group. MCF-7 cells induced by cisplatin were defined as Ci-Apoptotic-MCF-7, and the exosomes derived from macrophages co-cultured with Ci-Apoptotic- MCF-7 cells as the Ci-Co-exo group, and exosomes from the macrophage alone as the Ci-Mac-exo. Briefly, centrifugation was used to remove cell debris $(500 \mathrm{~g}$ for $10 \mathrm{~min}$ ) and the supernatant was transferred and centrifuged again $(16,000 \mathrm{~g}$ for $20 \mathrm{~min})$. Supernatants were filtered through a $0.22 \mu \mathrm{m}$ filter and exosomes were pelleted by ultracentrifugation $(100,000 \mathrm{~g}$ for 70 min). Exosome pellets were resuspended in PBS. The quantity of exosome protein was assessed using the bicinchoninic acid (BCA) kit. Exosomes $(100 \mu \mathrm{g} / \mathrm{ml})$ were added to naïve MCF-7 or MDA-MB-231 cells and adapted to $10 \%$ exosomes-depleted FBS medium for $48 \mathrm{~h}$. Mac-exo and Co-exo treated MCF-7 cells were abbreviated as MCF-7Mac-exo and MCF-7Co-exo, Mac-exo and Co-exo treated MDA-MB-231 cells were abbreviated as MDA-MB-231 Mac-exo and MDA-MB-231Co-exo, and Ci-Mac-exo and Ci-Co-exo treated MCF-7 cells were abbreviated as

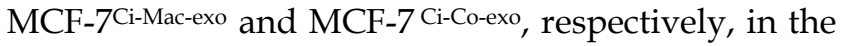
experiments described below.

\section{Transmission electron microscopy (TEM) and DiD labeling of exosome}

A droplet of purified exosomes was resuspended in $1 \%$ glutaraldehyde in $0.1 \mathrm{M}$ sodium phosphate buffer and placed on 300-mesh carbon-coated polyvinyl formal copper grids (Formvar, Electron Microscopy Sciences, Hatfield, PA) and left to adsorb for $30 \mathrm{~min}$. After excess buffer was removed, dry grids were washed with deionized water and stained with $1 \%$ aqueous uranyl acetate before TEM analysis [18]. To track their location, isolated exosomes were labeled with $5 \mu \mathrm{M}$ DiD (AAT Bioquest ${ }^{\circledR}$, Inc.) in $100 \mu \mathrm{l}$ PBS by incubating at $37^{\circ} \mathrm{C}$ for $20 \mathrm{~min}$. Subsequently, the incubated solution was centrifuged by ultracentrifugation $(100,000 \mathrm{~g}$ for $70 \mathrm{~min})$. After aspirating the supernatant, the pellet was resuspended and added to naïve MCF-7 cells for co-culture for $3 \mathrm{~h}$. Treated MCF-7 cells were fixed 
with $4 \%$ paraformaldehyde, stained with DAPI (Solarbio ${ }^{\circledR}$ Life Sciences, China), and images were obtained using a confocal microscope (Leica TCS SP8 STED 3X).

\section{Cell proliferation and analysis of cell cycle phase}

Cells were seeded at 10,000 cells/well into 96 well plates. At the time of the assay, $20 \mu \mathrm{l}$ of CellTiter $96{ }^{\circledR}$ AQueous One Solution (Promega Biotech Co, Ltd) was added to each well and incubated for $4 \mathrm{~h}$. Absorbance was measured at $490 \mathrm{~nm}$ using an iMark Microplate Absorbance Reader (Bio-Rad, USA). Cell cycle analysis was performed using PI staining. Exosome-treated MCF-7 cells $\left(1 \times 10^{6}\right)$ were collected and fixed in ice-cold $70 \%$ ethanol at $4^{\circ} \mathrm{C}$ overnight. This was followed by centrifugation at $3000 \mathrm{rpm}$ for 5 min and treated with $100 \mu \mathrm{g} / \mathrm{ml}$ RNaseA (Amresco ${ }^{\circledR}$ Life Science, USA) to eliminate interference by RNA, stained with PI. Stained cells were analyzed with a FACSCalibur. FCS Express version 3 (De Novo Software) was used to analyze the data.

\section{Colony formation assay}

Exosome-treated MCF-7 cells were detached and resuspended in DMEM with 10\% FBS and were diluted to yield appropriately 400 cells per $10 \mathrm{~cm}$ plate containing $10 \mathrm{~mL}$ of medium. Cells were incubated for 8 days to yield sufficiently large clones. At the indicated time points, cells were fixed with methanol and stained using crystal violet. Images were obtained using a camera, with colonies counted using Image-Pro Plus 6.0 analysis software [19].

\section{In vitro cell migration and invasion assay}

The migration and invasion of cells treated with or without exosomes were measured using the Transwell migration/invasion assay according to previously described procedures [20]. Briefly, invasion chambers containing polycarbonate filters $(8$ $\mu \mathrm{m}$ pore size; Corning Costar) were placed into wells. BD Matrigel matrix melted at $4^{\circ} \mathrm{C}$ was diluted 1:8 with pre-cooled serum-free DMEM medium. $100 \mu$ diluted Matrigel matrix was added to each upper chamber and incubated for $2 \mathrm{~h}$ in a $37^{\circ} \mathrm{C}$ incubator (This step is only used for the invasion assay, and is not required for the migration assay). Treated MCF-7 or MDA-MB-231 cells $\left(2 \times 10^{4}\right)$ were then seeded into serum-free medium in the upper chamber. DMEM, containing $10 \%$ FBS as a chemoattractant, was added to the receiver wells. Following $12 \mathrm{~h}$ incubation, cells on the upper-side of the membrane and the Matrigel matrix were gently removed and cells that had migrated to the underside through the Matrigel were fixed with methanol, stained with crystal violet and counted from 5 randomly chosen microscopes fields for each group [21]. Image-Pro Plus 6.0 software was used to analyze the images.

\section{Quantitative RT-qPCR}

Total RNA was extracted with Trizol (Invitrogen, USA) according to the manufacturer's instructions. cDNA was synthesized using the RevertAid First Strand cDNA Synthesis Kit (Thermo Scientific, USA). RT-qPCR were performed using the Applied Biosystems StepOne ${ }^{\mathrm{TM}}$ Real-Time RT-PCR System with PowerUp ${ }^{\mathrm{TM}}$ SYBR® Green Master Mix (ABI, USA). Primers and annealing temperatures are listed in Table 1. Glyceraldehyde 3-phosphatedehydrogenase (GAPDH) was used as the internal control. Data were normalized to the GAPDH expression levels and are presented as the averages from three experiments. The relative gene expression levels were calculated using the comparative $\mathrm{Ct}$ $(\Delta \Delta \mathrm{Ct})$ method, with the relative expression

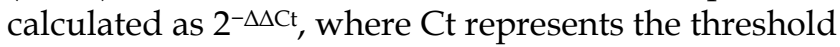
cycle.

Table 1. Primers used for RT-qPCR analysis of gene expression.

\begin{tabular}{|c|c|c|}
\hline Gene & Primer & $\operatorname{Tm}\left({ }^{\circ} \mathrm{C}\right)$ \\
\hline $\begin{array}{l}\text { STAT3 } \\
\text {. }\end{array}$ & $\begin{array}{l}\text { F- GAGAAGGACATCAGCGGTAAG } \\
\text { R-AGTGGAGACACCAGGATATTG }\end{array}$ & 60 \\
\hline MMP2 & $\begin{array}{l}\text { F- TGTGTTGTCCAGAGGCAATG } \\
\text { R-ATCACTAGGCCAGCTGGTTG }\end{array}$ & 60 \\
\hline MMP9 & $\begin{array}{l}\text { F- CGCAGACATCGTCATCCAGT } \\
\text { R-GGACCACAACTCGTCATCGT }\end{array}$ & 60 \\
\hline CyclinD1 & $\begin{array}{l}\text { F- TCGCCACCTGGATGCTGGAGGTCTG } \\
\text { R- CACCAGGAGCAGCTCCATTTGCAGCAG }\end{array}$ & 60 \\
\hline IL-6 & $\begin{array}{l}\text { F- CAACGATGATGCACTTGCAGA } \\
\text { R- CTCCAGGTAGCTATGGTACTCCAGA }\end{array}$ & 64 \\
\hline GAPDH & $\begin{array}{l}\text { F- GCACCGTCAAGGCTGAGAAC } \\
\text { R- TGGTGAAGACGCCAGTGGA }\end{array}$ & 60 \\
\hline
\end{tabular}

\section{Western blotting}

Western blotting was performed as previously described [22]. Briefly, $30 \mu \mathrm{g}$ of protein was separated by SDS-PAGE and electro-transferred to a PVDF membrane. Membranes were blocked for $2 \mathrm{~h}$ with $5 \%$ $\mathrm{w} / \mathrm{v}$ nonfat dry milk and then incubated overnight at $4^{\circ} \mathrm{C}$ with primary antibodies. Antibodies against HSP70, TSG101, CD9, STAT3, p-STAT3, CyclinD1, MMP2, MMP9 and GAPDH were obtained from Abcam. Antibody binding was detected after incubation with HRP-linked secondary antibodies by luminal chemiluminescence ChemiDoc XRS after reaction with super ECL plus.

\section{Nude Mice Xenografts Assay and Tumor Metastasis Assay}

Cells $\left(1 \times 10^{6}\right)$ suspended in $200 \mu$ PBS were injected subcutaneously into the right armpit of BALB/c nude mice (female, 6-8 weeks old). After 4 weeks, mice were sacrificed by cervical dislocation, photographs of the tumors were taken with a digital 
camera, and tumors were excised to determine their weight and volume. The experimental metastasis model was performed as previously described with some modifications [23]. Briefly, BALB/c nude mice were injected with cell suspension containing $1 \times 10^{6}$ cells via the tail vein. After 8 weeks, mice were sacrificed by cervical dislocation and the lungs and livers from the mice in each group were harvested and fixed in $4 \%$ paraformaldehyde, after fixing, the normal lung tissue appeared to be brownish yellow, while the cancerous lesions were raised and white. Subsequently, the sizes of the visible nodules were measured using a vernier caliper and recorded for statistics. The lung surface metastases were independently measured by two investigators and the mean was calculated. After photographing, organs were embedded in paraffin, serially sectioned, HE-stained paraffin sections were examined to evaluate the presence and number of metastatic tumors and observed under a light microscope.

\section{Statistical analysis}

All experiments were conducted in at least 3 independent cultures. Data are represented as means \pm S.E. $(\bar{x} \pm s)(n=3)$. Statistical differences were determined by one-way ANOVA. $\mathrm{p}<0.05$ was considered statistically significant.

\section{Results}

\section{Verification of THP-1-derived macrophages and apoptosis of MCF-7 cells in vitro}

Since all macrophages express the markers CD163 [24], CD68 [25], CD204 [26] and CD206 [27], we used these as markers for the differentiation of THP-1 cells into macrophages. As shown in Figure 1A, the THP-1-derived macrophages express higher levels of the cell surface markers CD163, CD68, CD204 and CD206 compared to monocytic THP-1 cells. To mimic a chemotherapy microenvironment for breast cancer cells, we used $\mathrm{H}_{2} \mathrm{O}_{2}$ and cisplatin, which are toxic to cells and induces hypoxia [28, 29], to promote apoptosis in MCF-7 cells, thus establishing an in vitro apoptotic cancer cell model. Results from flow cytometry showed that $\mathrm{H}_{2} \mathrm{O}_{2}$ induced apoptosis in the MCF-7 cells, with $0.3 \mathrm{mM} \mathrm{H} \mathrm{H}_{2}$ treatment for $24 \mathrm{~h}$ generating nearly $100 \%$ apoptosis in these cells (Figures 1B-C), with results from the cisplatin induced-apoptotic MCF-7 cells shown in Figures S1A-B. All further experiments used $0.3 \mathrm{mM} \mathrm{H}_{2} \mathrm{O}_{2}$ or $25 \mu \mathrm{M}$ cisplatin to generate apoptotic breast cancer cells.
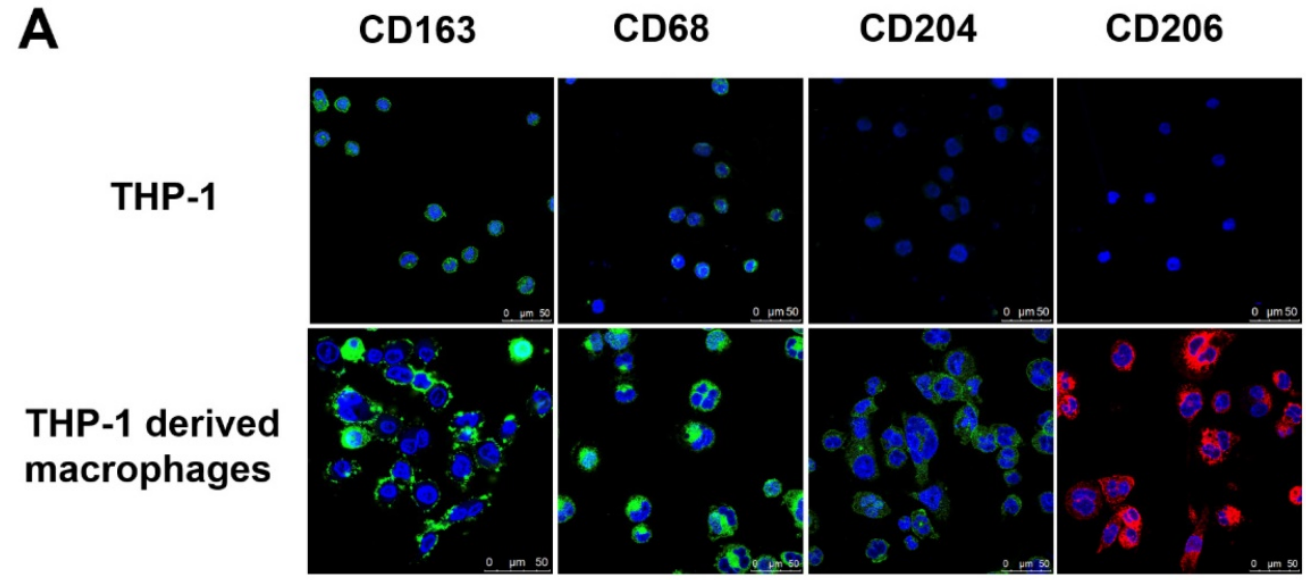

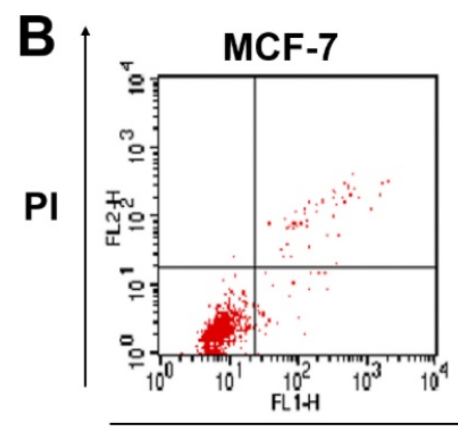

\section{Annexin V}

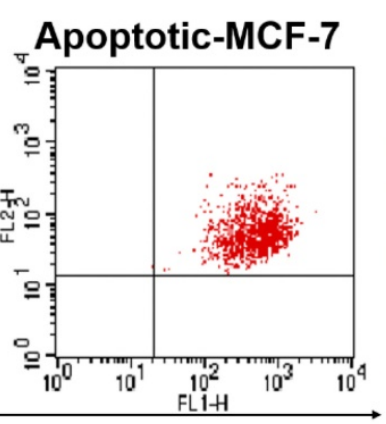

MCF-7 cells

in vitro. (A) Cells were fixed and immunolabeled for the detection of CD163, CD68, CD204 and CD206 using specific antibodies (labeled green or red). Nuclei were stained with DAPI (blue). Scale bar is 50 um. (B) Flow cytometry analysis of Annexin V-FITC/PI co-stained untreated (left panel) and apoptotic (right panel) MCF-7 cells. (C) Quantification of the flow cytometry results. Results are typical of three independent experiments. Data represent means \pm S.E. $(\bar{x} \pm s)(n=3)$. *** $p<0.001$ indicates statistical significance of the apoptosis group to the untreated group. 


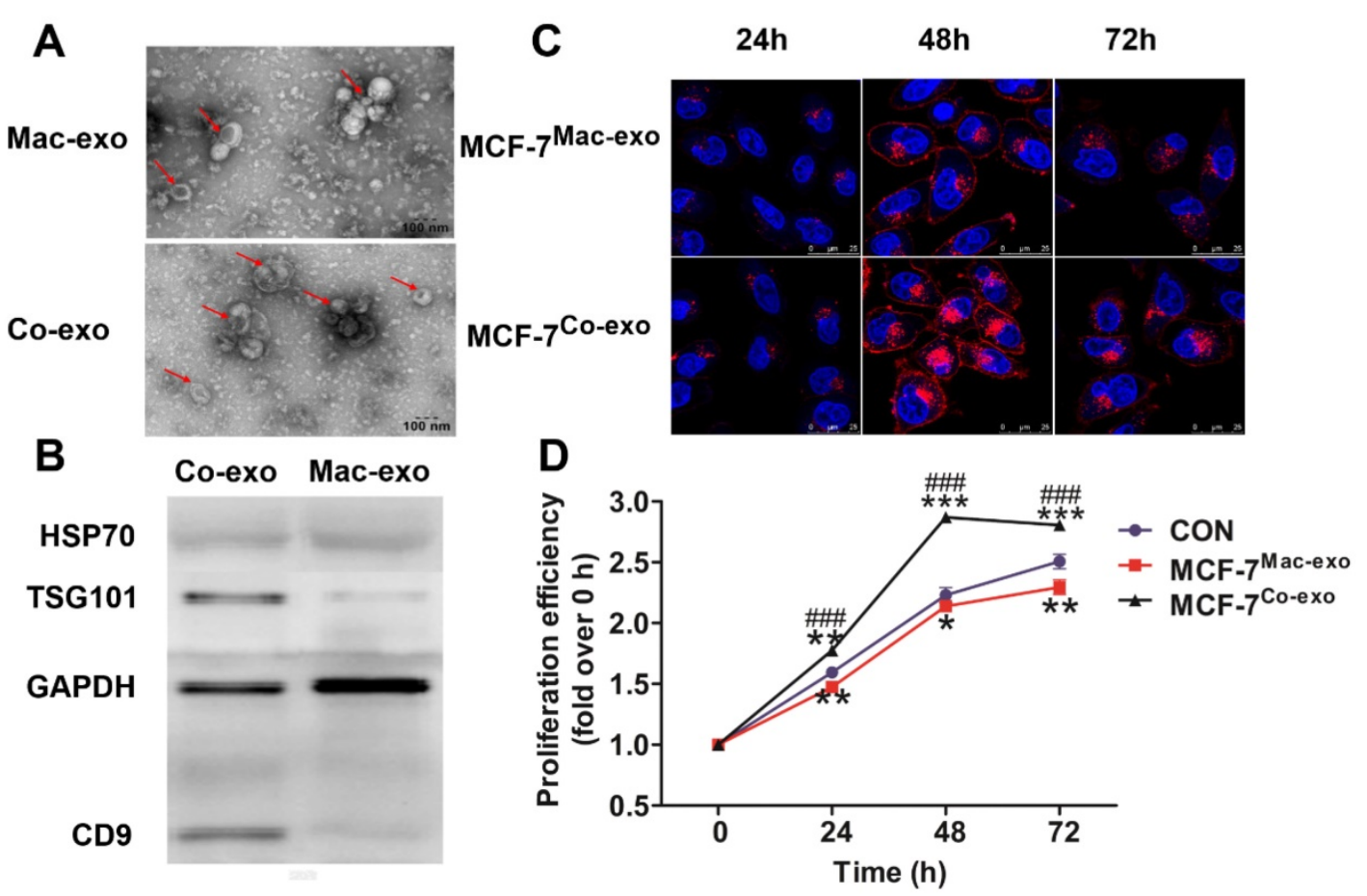

Figure 2. Characterization of exosomes and the co-culture of macrophage-derived exosomes increased the proliferation of MCF-7 cells. (A) Exosomes isolated from macrophages (Mac-exo) and co-cultured macrophages (Co-exo) imaged by TEM are approximately $100 \mathrm{~nm}$ in size. Scale bar $=100 \mathrm{~nm}$. (B) Levels of exosome markers HSP70, TSG101 and CD9 in Mac-exo (left lane) and Co-exo (right lane) groups were determined by Western blotting. (C) Confocal microscopy visualization of exosomes taken up by MCF-7 cells. Exosomes were stained with DiD dye, and then co-cultured with MCF-7 cells for $24 \mathrm{~h}, 48 \mathrm{~h}$ and $72 \mathrm{~h}$. Nuclei were stained with DAPI. Scale bar $=25 \mu \mathrm{m}$. (D) Proliferation of MCF-7 cells in control (CON), MCF-7Mac-exo and MCF-7Co-exo groups was measured over $72 \mathrm{~h}$ by MTS assay. Results are typical of three independent experiments. Data represent means \pm S.E. $(\bar{x} \pm s)(n=3) .{ }^{*} p<0.05,{ }^{*} p<0.01$ and ${ }^{* * *} p<0.001$ indicate statistical significance in comparisons of the MCF-7Mac-exo and MCF-7Co-exo groups to the CON group. ${ }^{\# \#} \mathrm{p}<0.001$ indicates statistical significance in comparisons of the MCF-7Co-exo group with the MCF-7Mac-exo group.

\section{Characterization of exosomes by TEM and Western blotting}

We characterized exosomes that had been purified by ultracentrifugation by TEM. Images showed that the exosomes were between $30-100 \mathrm{~nm}$ in diameter and had a round with cup-like concave morphology (Figure 2A), consistent with known exosome morphology [6]. In addition, Western blotting showed that the isolated exosomes were enriched with HSP70, TSG101 and CD9 (Figure 2B), which is consistent with previous reports [30], thus we concluded that both macrophages and macrophages exposed to apoptotic MCF-7 cells produce exosomes.

\section{Co-exo increases proliferation ability of breast cancer cells}

We next determined whether Mac-exo and Co-exo exosomes were taken up by MCF-7 cells. MCF-7 cells were incubated with exosomes labeled with $\mathrm{DiD}$ dye for $72 \mathrm{~h}$. DiD staining was observed by confocal microscopy in the MCF-7 cells exposed to both Mac-exo (upper panels) and Co-exo (lower panels) exosomes (Figure 2C) at $24 \mathrm{~h}, 48 \mathrm{~h}$ and $72 \mathrm{~h}$. Over time, the DiD dye appeared in the MCF-7 cells, with a peak at $48 \mathrm{~h}$ and lower slightly lower levels at 72 h. These data demonstrate that MCF-7 cells efficiently internalize these two groups of exosomes. Next, to further investigate the effects of these two groups of exosomes on the proliferation of MCF-7 cells, we co-cultured MCF-7 cells, in DMEM medium, with $10 \%$ exosome-depleted FBS, with $100 \mu \mathrm{g} / \mathrm{ml}$ of added exosomes for $72 \mathrm{~h}$. Control cells (CON group) were MCF-7 cells that were not exposed to exosomes. As shown in Figure 2D, MCF-7Co-exo cells displayed an increased proliferative rate, which was significantly more rapid than the $\mathrm{CON}$ group for all time points. In contrast, the proliferative ability of the MCF-7Mac-exo cells was significantly decreased at all time points. Moreover, this difference was most significant at $48 \mathrm{~h}$. Similar results were observed in our cisplatin-induced MCF-7 cell model and the $\mathrm{H}_{2} \mathrm{O}_{2}$-induced MDA-MB-231 cell model (Figures S1C and S3A). These results suggest that co-cultured macrophagesderived exosomes could promote the proliferation of breast cancer cells.

\section{Interleukin 6 (IL-6)/signal transducers and activators of transcription 3 (STAT3) signaling pathway was activated after breast cancer cells were co-cultured with Co-exo}

Since exosomes generated by co-culture of macrophages and apoptotic MCF-7 cells changed the proliferative ability of MCF-7 cells, this suggested that 
the exosomes stimulated the MCF-7 cells with a protein that induces proliferation. In our previous research we found that IL-6 could increase the phosphorylation of STAT3 to promote proliferation and metastasis in a chemotherapy microenvironment model [16], thus to determine whether the IL-6 pathway had been activated in the MCF-7 cells co-cultured with Co-exo, we examined the expression levels of the IL- 6 and STAT3 genes. As expected, the mRNA levels for IL-6 in the MCF-7Co-exo cells was much higher than in MCF-7Mac-exo and control cells (Figure 3A). However, no significant difference in the mRNA levels for STAT3 was observed in the three groups of cells (Figure 3B). Since activation of the STAT3 signaling pathway is due to the levels of phosphorylated STAT3 (p-STAT3), and not abundance of total STAT3, we then examined the phosphorylation status of STAT3 by Western blotting (Figure 3C). Consistent with the real-time RT-PCR results, no significant difference in total protein levels of STAT3 was detected among the three groups of cells, but the protein abundance of p-STAT3 in MCF-7Co-exo cells was higher than in the other two groups of cells, with MCF-7Mac-exo cells having the lowest levels (Figure 3D). Similar results were observed in our cisplatin-induced MCF-7 and in $\mathrm{H}_{2} \mathrm{O}_{2}$-induced MDA-MB-231 cell models (Figures S2 and S4). These results show that Co-exo stimulated breast cancer cells through cytokines, such as IL-6, to modify their proliferative and metastatic properties. According to the literature [31], STAT3 is the main transcription factor through which IL-6 signals in target cells, where it regulates many downstream target genes including those that regulate cell cycle and proliferation (e.g., CyclinD1) [32] and tumor metastasis (e.g., MMP2 and MMP9) [33]. Therefore, we next examined the cell cycle, clone formation and metastasis ability, and the expression of their corresponding genes, in MCF-7 cells exposed to Co-exo and Mac-exo exosomes, and control cells.

\section{Co-exo causes an accumulation of cells in the S-phase and alters the expression of CyclinD 1 to promote proliferation}

To evaluate the effects of exosomes on the cell cycle in MCF-7 cells, we performed a cell cycle analysis by flow cytometry. As shown in Figure 4A, a significant decrease in the number of cells in the G0/G1 phase and a significant increase in the number in S phase were observed for MCF-7Co-exo cells. But for the MCF-7Mac-exo cells, the opposite result was observed. The ability to form colonies in vitro is a key feature of cancerous cells and an indication of proliferation [34]. Therefore, we examined the colony forming potential of exosome-treated MCF-7 cells. As shown in Figures $4 \mathrm{~B}-\mathrm{C}$, the colony forming ability was

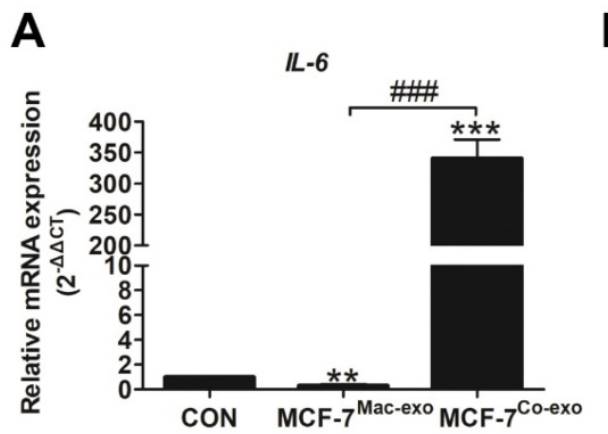

B
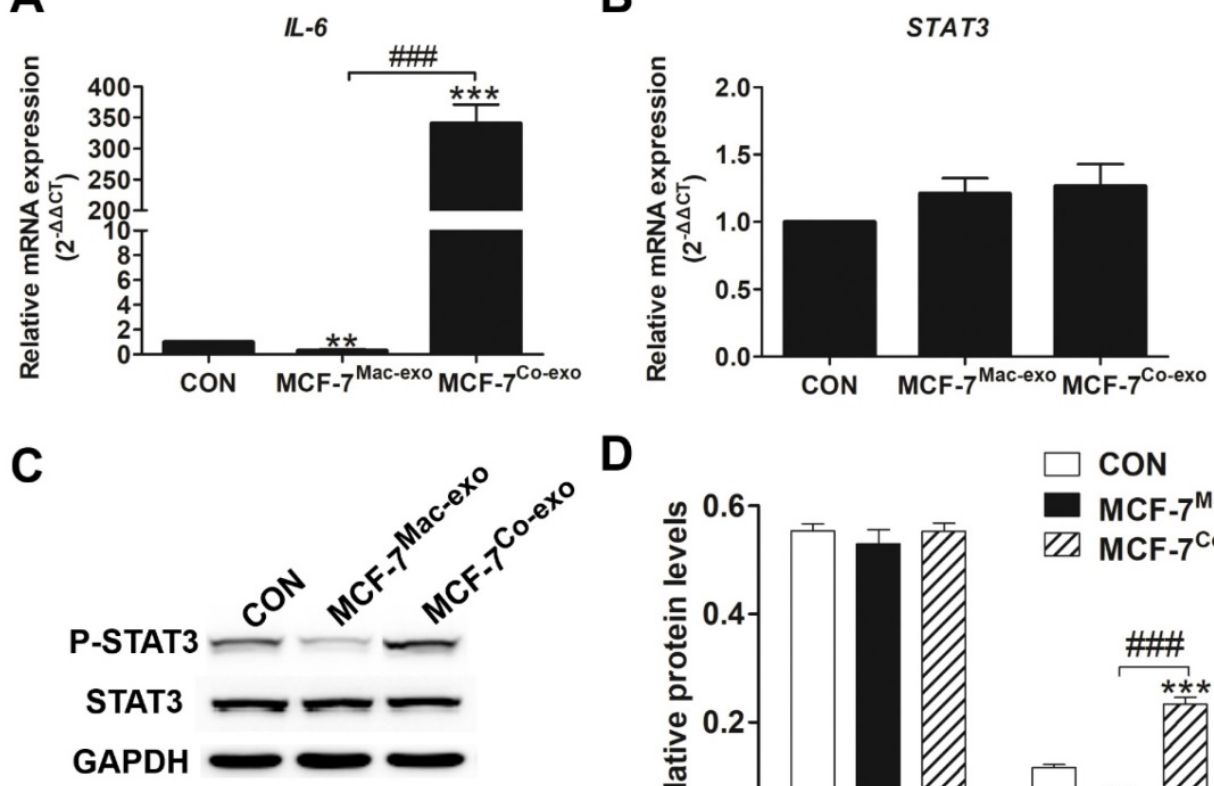

D

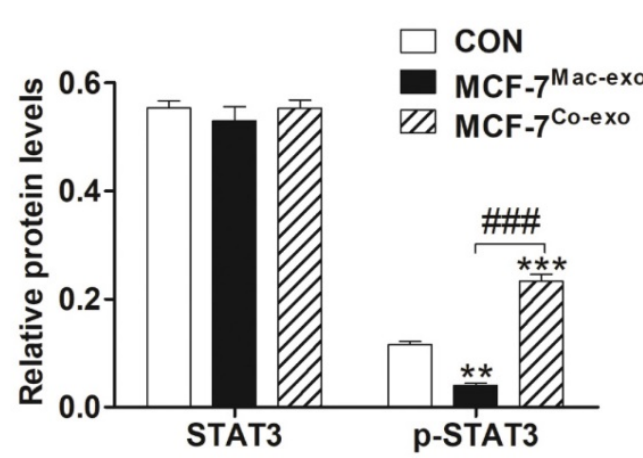

Figure 3. IL-6/ STAT3 signaling pathway is activated after MCF-7 cells are co-cultured with Co-exo. IL-6 (A) and STAT3 (B) mRNA levels were assessed using RT-qPCR assay in CON, MCF-7Mac-exo and MCF-7Co-exo cells. GAPDH was used as the internal standard. (C) Western blotting for STAT3 and P-STAT3, with GAPDH used as the loading control. (D) Bar charts illustrate the relative protein abundance of STAT3 and p-STAT3 compared to GAPDH in CON, MCF-7Mac-exo and MCF-7Co-exo cells based on densitometry of Western blotting. Results are typical of three independent experiments. Data represent means \pm S.E. $(\bar{x} \pm \mathrm{s})(\mathrm{n}=3)$. ${ }^{* *} \mathrm{p}<0.01$ and ${ }^{*} * \mathrm{p}<0.001$ indicate statistical significance for comparisons of the MCF-7Mac-exo and MCF-7Co-exo groups to the CON group. ${ }^{m} \mathrm{p}<0.001$ indicates statistical significance for comparisons of the MCF-7Co-exo group with the MCF-7Mac-exo group. 
significantly increased in MCF-7Co-exo cells compared with MCF-7Mac-exo and control cells. The MCF-7Mac-exo cells showed the lowest colony forming ability. This result is consistent with the proliferative capacity shown in Figure 2D. In carcinogenesis, obtaining proliferative capacity without external stimuli is an important step, and this is usually achieved as the consequence of oncogene activation, with CyclinD1 being well-known for its involvement in cell proliferation [35]. CyclinD1 is also the most crucial protein in the regulation of the cell cycle [36]. In our study, we found an increase in expression of Cyclin D1 at both the transcript and protein level in MCF-7Co-exo cells, with a decrease observed in MCF-7Mac-exo cells (Figures 4D-F). The G1/S-phase transition is a crucial checkpoint point in cell division and is often dysregulated in cancer cells [37]. Our results show that Co-exo causes an accumulation of cells in S-phase, altered expression of cell cycle proteins Cyclin D1, and these results strongly suggest that Co-exo promotes proliferation through the G1/S-phase transition in breast cancer cell lines.

\section{Co-exo promotes cellular migration and invasion and the expression of MMP2 and MMP9}

Breast cancer is the leading cause of cancer death in women worldwide, which is largely due to the metastatic property of this cancer [38]. Previous studies have shown that matrix metalloproteinases (MMPs), especially MMP -2 and MMP-9, play a major role in tumor invasion and metastasis [39]. As shown in Figures 5A-B, the migration and invasion abilities were both significantly increased in MCF-7Co-exo cells compared with the other two groups of cells, with the MCF-7Mac-exo cells showing the lowest levels. Similar findings were obtained in our cisplatin-induced MCF-7 and in a $\mathrm{H}_{2} \mathrm{O}_{2}$-induced MDA-MB-231 cell models (Figures S1D-E and S3B-C). Increased mRNA and protein levels for MMP2 and MMP9 were also seen in MCF-7Co-exo cells (Figures 5C-E). These results show that Co-exo promotes breast cells migration and invasion.
A

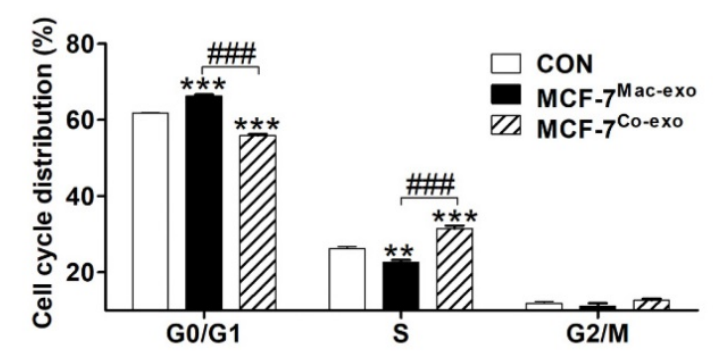

B

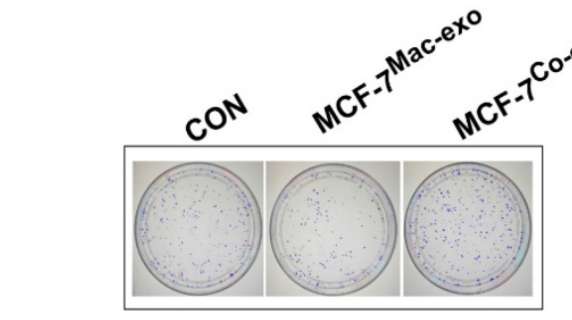

C

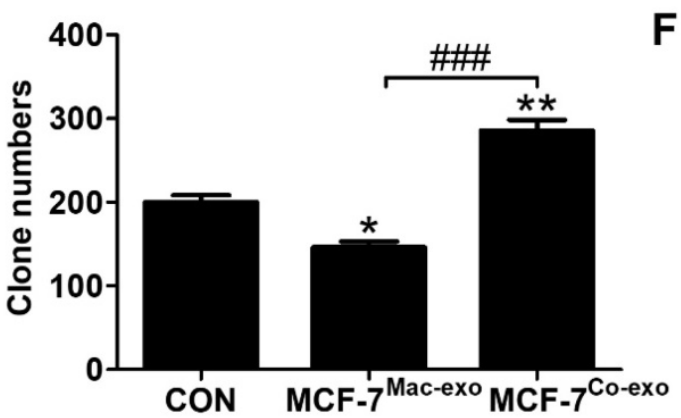

D

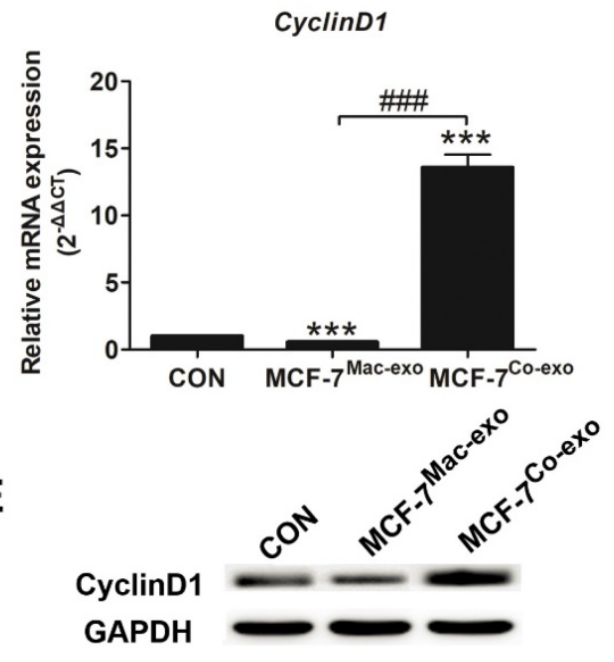

$\mathbf{F}$

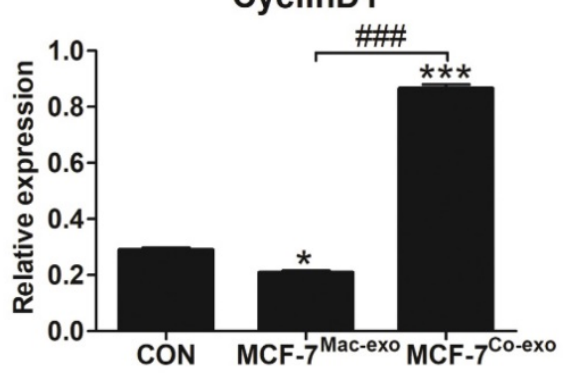

Figure 4. Co-exo causes the accumulation of cells in the S-phase and alters expression of CyclinD1. (A) Flow cytometric analysis of cell cycle phases in CON, MCF-7Mac-exo and MCF-7Co-exo cells. (B) Representative colony formation images and (C) quantification of CON, MCF-7Mac-exo and MCF-7Co-exo cells. Each bar represents average cell number of 5 fields. (D) mRNA level of CyclinDI was assessed using RT-qPCR assay in CON, MCF-7Mac-exo and MCF-7Co-exo cells. GAPDH was used as the internal standard. (E) Western blot analysis of CyclinDI with GAPDH used as the loading control. (F) Bar charts illustrate the relative protein abundance of CyclinDI compared to GAPDH in CON, MCF-7Mac-exo and MCF-7Co-exo cells based on densitometry of the Western blot results. Results are typical of three independent experiments. Data represent means \pm S.E. $(\bar{x} \pm s)(n=3) . *$ $\mathrm{p}<0.05,{ }^{* *} \mathrm{p}<0.01$ and ${ }^{* * *} \mathrm{p}<0.001$ indicate statistical significance for comparisons of the MCF-7Mac-exo and MCF-7Co-exo groups to the CON group. ${ }^{\# \#} \mathrm{p}<0.001$ indicates statistical significance for comparisons of the MCF-7Co-exo group with the MCF-7Mac-exo group. 
A
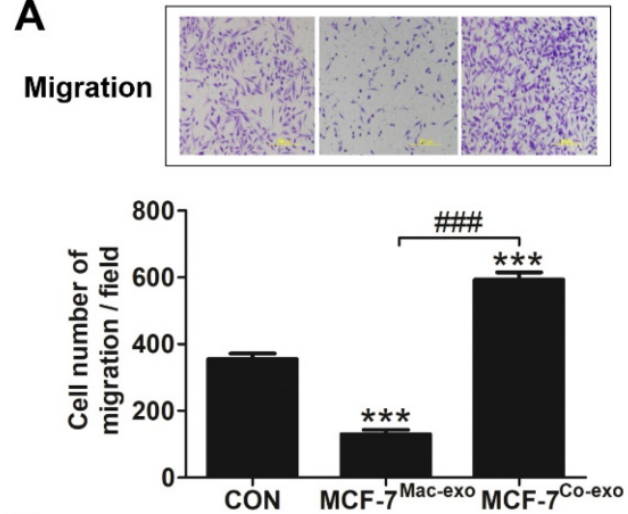

B
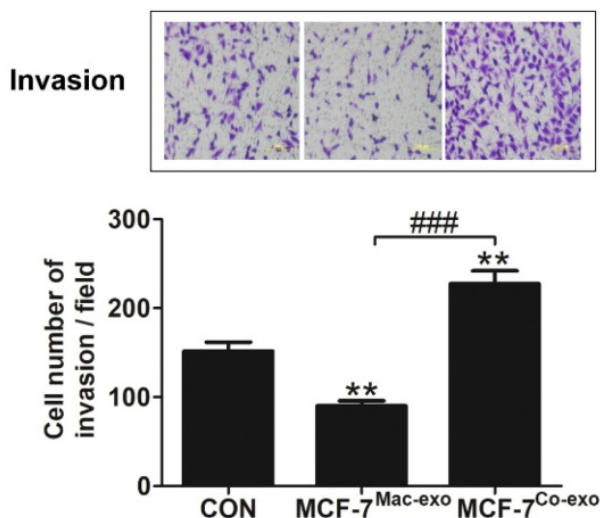

C

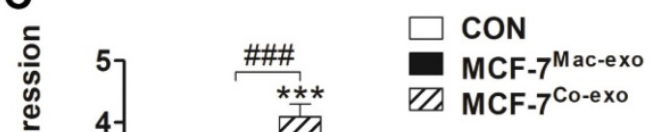

D

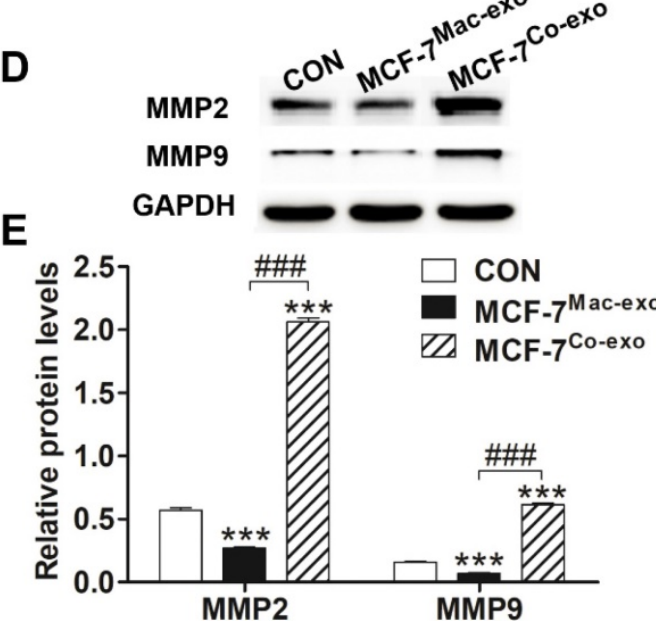

Figure 5. Co-exo promotes migration and invasion and increases the expression of MMP2 and MMP9. Representative images (upper panel) and quantification (lower panel) of migration (A) and invasion (B) assays of CON, MCF-7Mac-exo and MCF-7Co-exo cells. Each bar represents the average number of cells from 5 fields. (C) mRNA levels of MMP2 and MMP9 were assessed using RT-qPCR assay in CON, MCF-7Mac-exo and MCF-7co-exo cells. GAPDH was used as the internal standard. (D) Western blotting of MMP2 and MMP9, with GAPDH used as the loading control. (E) Bar charts illustrate relative protein abundance of MMP2 and MMP9 compared to GAPDH in CON, MCF-7Mac-exo and MCF-7Co-exo cells based on densitometry of the Western blots. Results are typical of three independent experiments. Data represent means $\pm S . E .(\bar{x} \pm \mathrm{s})(\mathrm{n}=3)$. ${ }^{* *} \mathrm{p}<0.01$ and ${ }^{* * *} \mathrm{p}<0.001$ indicate statistical significance for comparisons of the MCF-7Mac-exo and MCF-7Co-exo groups to the CON group. \# $\mathrm{p}<0.001$ indicates statistical significance for comparisons of the MCF-7Co-exo group with the MCF-7Mac-exo group.

\section{Co-exo increases the tumorigenicity of MCF-7 cells in vivo}

To determine whether Co-exo influences the malignancy of MCF-7 cells, we tested the tumorigenicity of MCF-7 cells exposed to exosomes using the subcutaneously injected nude mice model. Tumor growth curves showed that MCF-7 cells cultured in normal media are capable of forming neoplasm by two weeks, although they grow at a slow rate. CON and MCF-7Mac-exo cells did not significantly change the growth rate of the neoplasm; however, tumor growth was dramatically increased in MCF-7Co-exo cells over two weeks (Figure 6A). As expected, tumors from the MCF-7Co-exo cells were larger and heavier than those from the other two groups of cells, with decreased tumor weight (Figure 6B) and size (Figure 6C) were seen for the MCF-7Mac-exo cells compared to the CON cells. As previously described, most human tumor xenograft experiments have employed subcutaneous injection procedures, but the main limitation of this technique is the lack of metastasis from the subcutaneous site [40]. Consistent with the literature, no lung (Figure
6D) or liver (Figure 6E) metastases were observed in our experiments.

\section{Co-exo improves metastatic ability of MCF-7 cells in vivo}

The possibility of producing experimental metastasis by intravenous injection of cells in the nude mice has been known for a long time [41], thus we used the tail vein injection method to examine the metastatic ability of human breast cancer cells in vivo using nude mice. Extremely obvious nodules were observed on the surface of the lung in MCF-7co-exo cell treated mice, and they were significantly increased in number and size compared to those seen in MCF-7Mac-exo cell and CON cell treated mice (Figure 7A). Moreover, normal lung tissue was invaded by the metastases with very little normal tissue remaining in the MCF-7Co-exo treated mice (Figure 7A). The volumes of the metastatic growths in the lung was determined. Our results indicated that the volume of metastatic nodules in MCF-7Co-exo cell treated mice was significantly greater than those seen in MCF-7Mac-exo cell CON cell treated mice, with the MCF-7Mac-exo cell treated mice having smaller nodules 

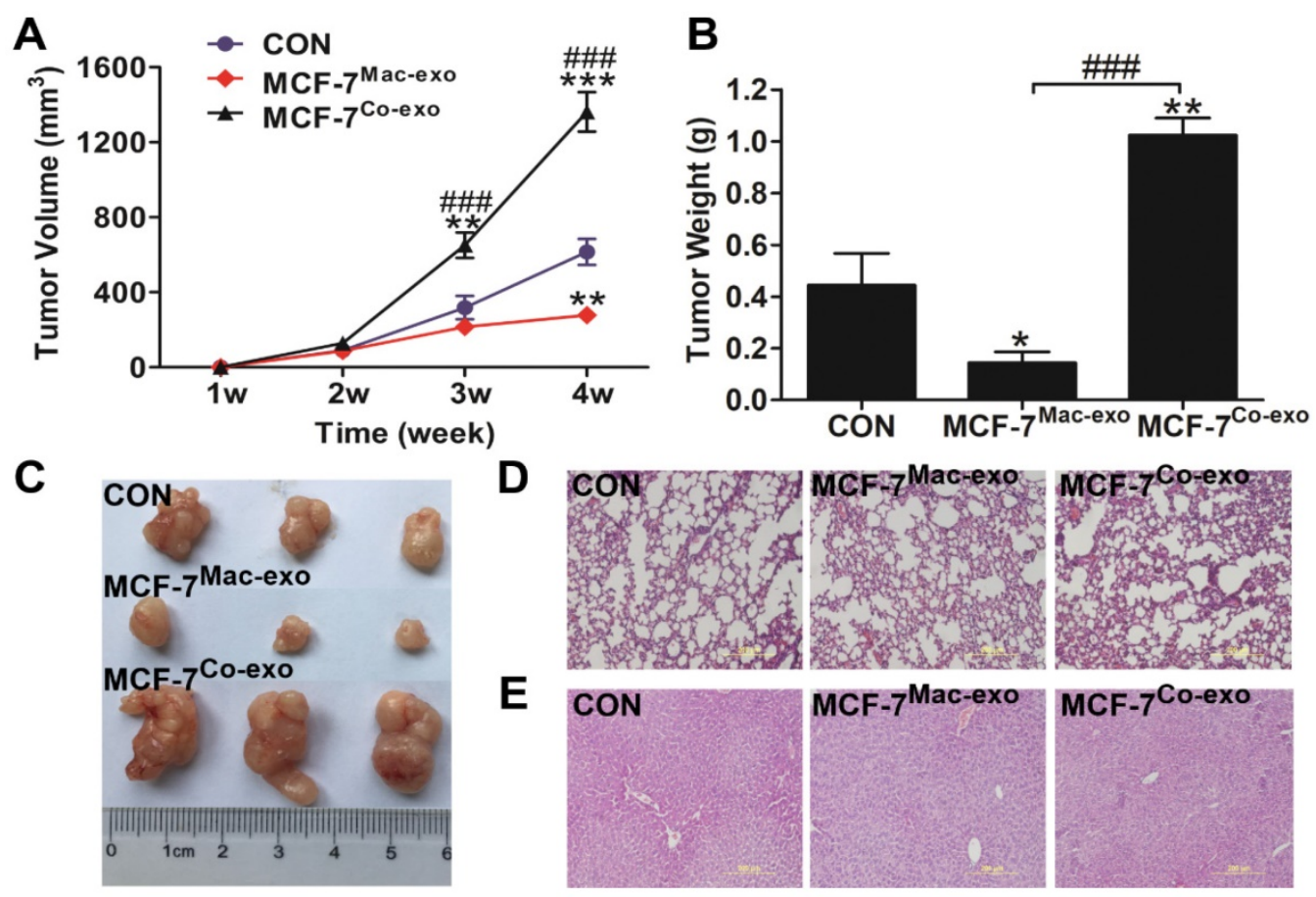

Figure 6. In vivo tumorigenicity assay of MCF-7 cells treated with exosomes. (A) Growth curves for tumors generated by MCF-7 cells grown with three types of exosomes. Width and diameter of tumors were measured using vernier caliper, and tumor volume was calculated using the formula $1 / 2 \times a \times b 2$, where "a" is the long tumor axis and " $b$ " is the short tumor axis. (B) Tumor weights were measured after excising from nude mice, $n=5$. (C) Images of tumors from the three groups of nude mice. Results are typical of three independent experiments. (D) and (E) HE staining of lungs and livers from three groups of nude mice (scale bar $=200 \mu \mathrm{m}$ ). Results are typical of three independent experiments. Data represent means \pm S.E. $(\bar{x} \pm s)(n=3){ }^{*} \mathrm{p}<0.05, * * 0.01$ and ${ }^{* * * *} \mathrm{p}<0.001$ indicate statistical significance in comparisons of the MCF-7Mac-exo and MCF-7Co-exo groups to the CON group. $\mathrm{p}<0.001$ indicates statistical significance in compassion between the MCF-7Co-exo group and the MCF-7Mac-exo group.

than the CON cells (Figure 7B). In addition, we also examined changes in the body weights in the three groups of nude mice during the 8 weeks after the tail vein injections. No significant changes in body weight were seen before week 5 . From week 6, the body weights of nude mice with MCF-7Co-exo cells decreased significantly. The weights of nude mice with $\mathrm{CON}$ cells only showed a non-significant decrease, while no change in body weights were seen in mice with MCF-7Mac-exo cells. By week 8 , the weights of nude mice with MCF-7Co-exo cells were much lower than those with the other two types of cells, and the health of these nude mice was significantly worse (Figure 7C). Migration of tumor cells in the lung was detected by staining with Hematoxylin-eosin (HE). Our results showed that MCF-7Co-exo cell-treated mice have more metastatic lesions and a larger area of metastases in their lung tissues compared with the other two groups of mice, with metastases rarely seen in the MCF-7Mac-exo cell-treated mice. Under the light microscope, metastases were darker colored and their cell morphologies were irregular compared to normal lung tissue. The amount of lung tissue invaded, and the size of the metastases was largest in the MCF-7Co-exo cell-treated mice, where little normal lung tissue remained. The location and sizes of the metastases in the lung tissue were examined at different magnifications in the mice (Figure 7D). In contrast to the lung, no tumor metastasis was found in the livers of three groups of nude mice, and the morphology and staining properties of the hepatocytes appeared normal (Figure 7E). In summary, these results suggest that macrophages co-cultured with apoptotic MCF-7 cells yield exosomes that not only promote tumor growth, but also increase the metastatic ability of MCF-7 cells in vivo, whereas exosomes from normal macrophages possess the opposite effects.

\section{Discussion}

In the current study, we have shown that the exposure of macrophages to apoptotic MCF-7 or MDA-MB-231 cells leads to changes in the exosomes that they secrete, such that they enhance STAT3 signaling to promote breast cancer proliferation and metastasis. Exosomes from different sources in the tumor microenvironment play different regulatory roles in the growth and metastasis of tumors. Recently, a study revealed that exosomes derived from lung metastasis subpopulations of breast cancer cells promote tumor self-seeding [42]. Interestingly, macrophages-derived exosomes have dualistic role in preventing and supporting tumor progression [43]. A study has suggested that tumor necrosis factor-like weak inducer of apoptosis (TWEAK) stimulated macrophage-derived exosomes inhibit the metastasis 
of ovarian tumor cells both in vitro and in vivo by transferring an exosomal miR-7 into epithelial ovarian cancer cells [44]. Other researchers have found that tumor-associated macrophages support the aggressiveness of gastric cancer by secreting exosomes that transfer functional miR-21 both in vivo and in vitro [45]. However, few studies have examined the role of exosomes derived from cancer cells during or after chemotherapy. As our previous work [16] showed that macrophages stimulated by apoptotic MCF-7 cells secrete IL-6, which activates STAT3 phosphorylation leading to the activation of cancer stem cells and the promotion of cancer development, we hypothesized that after chemotherapy, macrophages in breast cancer patients might be affected by apoptotic tumor cells and change their characteristics, which would then secrete exosomes that enhance tumor recurrence and metastasis.
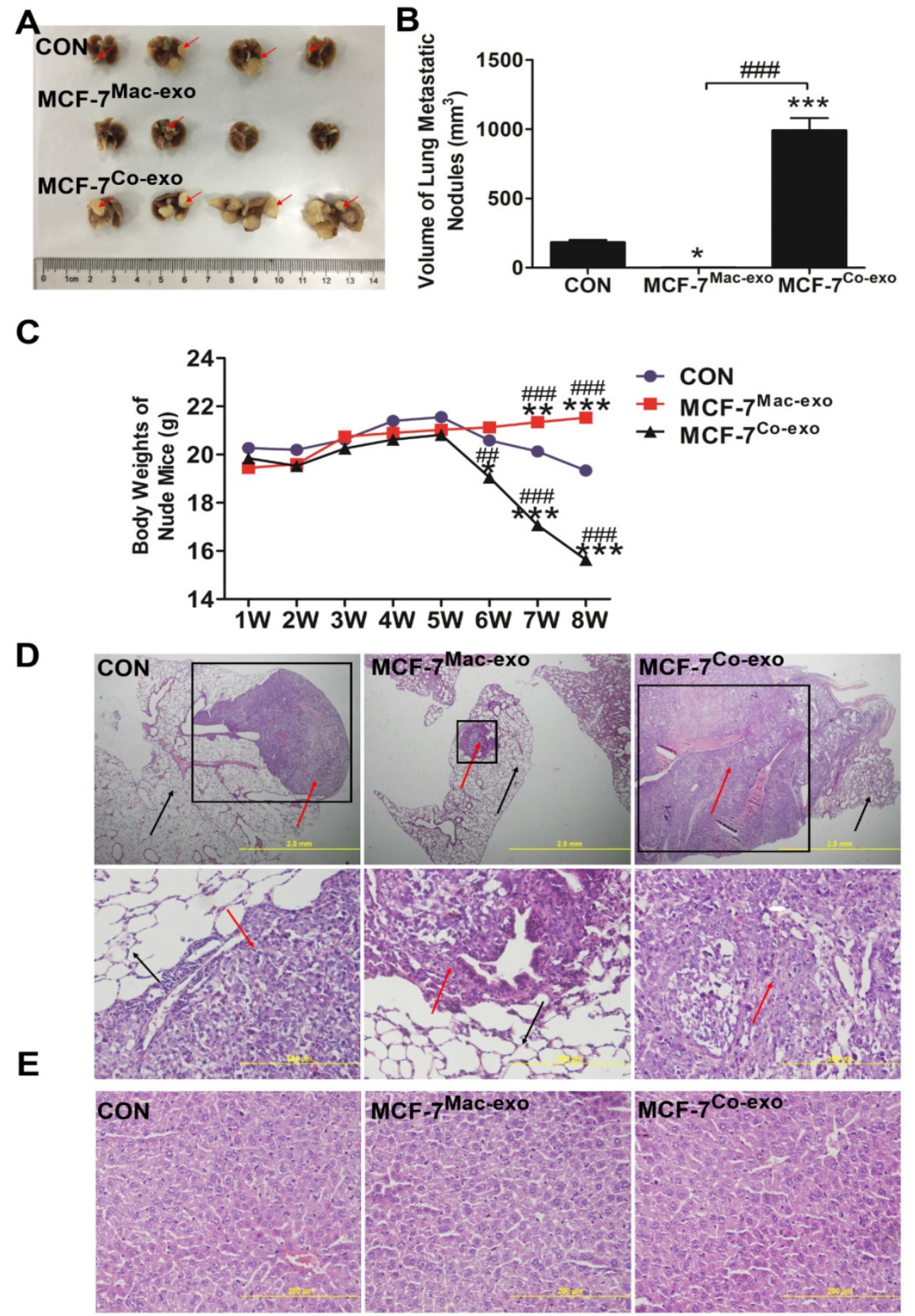

Figure 7. In vivo metastatic ability of MCF-7 cells treated with exosomes. (A) Macroscopic view of metastatic nodules in the lungs from three groups of nude mice. Red arrows indicate metastatic nodules on the surface of the lungs. (B) Quantification of the metastatic nodules in lunges in the three groups of mice $(n=4)$. (C) Weights of nude mice in the three groups were measured over 8 weeks after the vein injection, $n=4$. HE staining of paraffin sections from lungs (D) and livers (E) of the three groups of nude mice. Metastases in lungs are indicated by the black-bordered box (upper panels) (scale bar $=2 \mathrm{~mm}$ ). The red arrows indicate abnormally shaped tumor cells, and the black arrows indicate normal alveolar cells (right lane) (scale bar $=200 \mu \mathrm{m}$ ). No metastases were found in the liver (lower panels) (scale bar $=200 \mu \mathrm{m}$ ). Results are typical of three independent experiments. Data represent means \pm S.E. $(\bar{x} \pm s)(n=3) .{ }^{*} p<0.05$ and ${ }^{* * *} p<0.001$ indicate statistical significance in comparisons of the MCF-7Mac-exo and MCF-7Co-exo groups to the CON group. \#\#\# $\mathrm{p}<0.001$ indicates statistical significance in compassion between the MCF-7Co-exo group and the MCF-7Mac-exo group. 


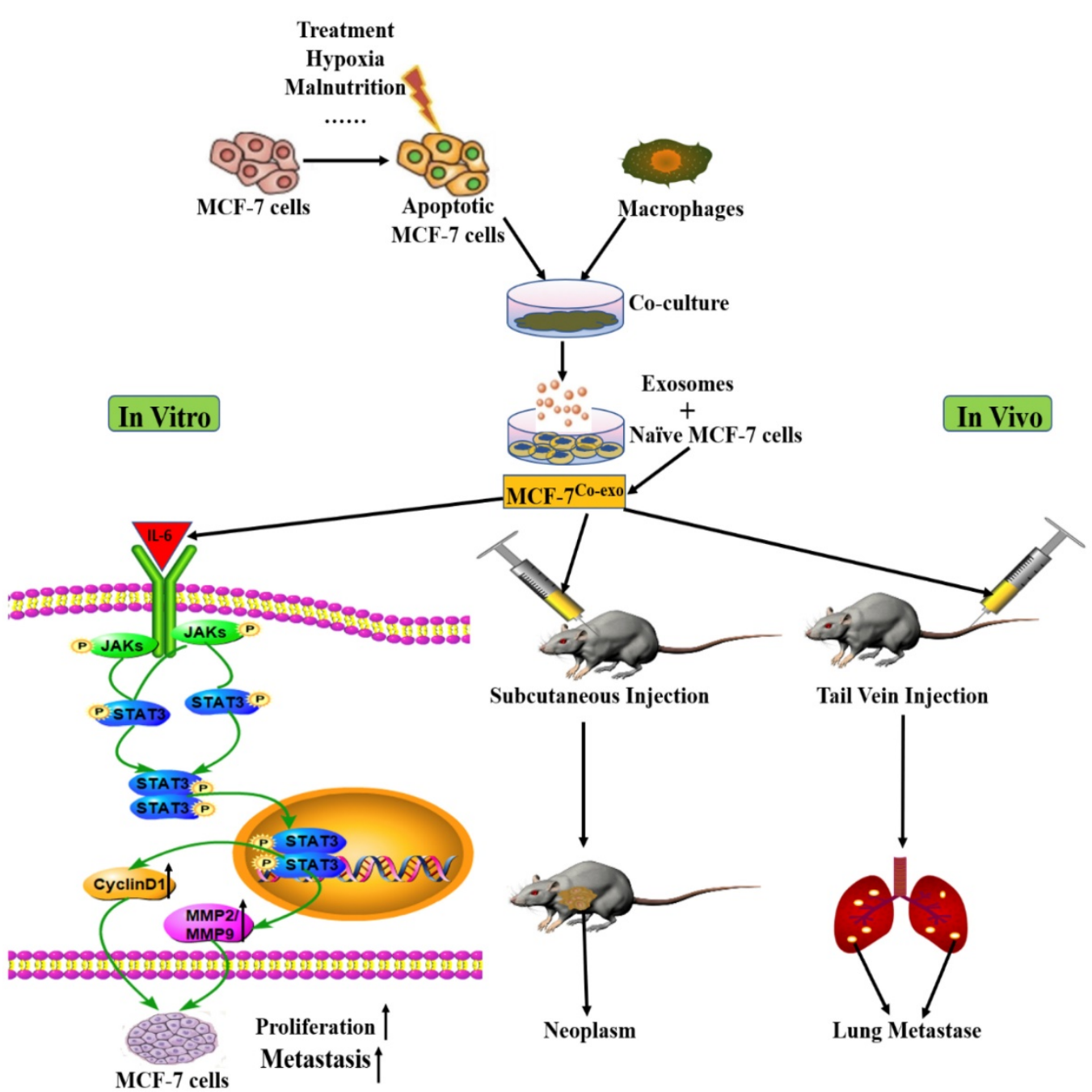

Figure 8. Possible mechanism for increased in vitro and in vivo breast cancer proliferation and metastasis by exposure to exosomes secreted by macrophages co-cultured with apoptotic MCF-7 cells. First, external (e.g., treatment, hypoxia) or internal (e.g., tumor malnutrition owing to outgrowth of the nutrition supply) stress induces apoptosis of tumor cells. Macrophages co-culture with the apoptotic tumor cells, which are the secreted modified exosomes. These exosomes can then influence naïve MCF-7 cells (MCF-7Co-exo cells). To investigate whether the proliferative and metastatic abilities of the Co-exo treated MCF-7 cells have changed, we conducted both in vitro and in vivo experiments. Increased expression of IL-6 in MCF-7Co-exo cells activate STAT3 signaling and promote expression of CyclinD1 and MMP2/MMP9 to improve proliferation and metastasis in vitro. Together, in vivo subcutaneous injections, forming neoplasms, and tail vein injections, causing lung metastases, in nude mice suggest that the proliferative and metastatic abilities of MCF-7Co-exo cells has increased.

Our experimental data show that the IL-6/STAT3 signaling pathway can be differentially regulated by exosomes from macrophages that have or have not been exposed to apoptotic breast cancer cells. The IL-6 and STAT3 signaling pathway is one of the most important signaling pathways regulating physiological functions [46]. STAT3 is a latent transcription factor found in the cytoplasm of cells, which is activated by tyrosine phosphorylation, leading to dimerization, nuclear translocation, DNA binding, and gene activation [47]. STAT3 is critically involved, primarily through differential gene regulation, with almost all aspects of tumorigenesis, including cell cycle progression, tumor invasion and metastasis, host immune system evasion, and tumor angiogenesis [48-50]. IL-6 expression is implicated in the regulation of tumor growth and metastatic spread [51]. By combining with their ligand-specific binding subunit, IL-6 use the common receptor gp130 as the signaling subunit to activate Janus kinase (JAK1 and JAK2) as well as tyrosine kinase 2 (Tyk2) [52]. JAK activation leads to phosphorylation of gp130 and recruitment and phosphorylation of STAT3 $[53,54]$. In our experiments, IL-6 gene expression was significantly increased (Figure 3A) and the level of pSTAT3 was higher in the Co-exo exosome treated MCF-7 cells.

The IL-6/STAT3 signaling pathway promotes cancer progression through transcription of target genes, including CyclinD1, which is an important regulatory gene in the STAT3 signaling pathway [55]. CyclinD1 is expressed during the early phase of the cell cycle, before the restriction point, beyond which cells are committed to enter S phase [56]. CyclinD1 is the most commonly reported overexpressed cyclin in cancer, where its overexpression accelerates the cell 
cycle, leading to persistent abnormal proliferation, and is associated with advanced local invasion and the presence of lymph node metastases [57]. In previous studies, it was found that MMP9 and MMP2 are important in cancer invasion and metastasis by degrading the extracellular matrix (ECM) and basement membrane [58]. It should be noted that, STAT3 signaling pathway directly regulates MMP-2 expression, tumor invasion, and metastasis, and that STAT3 activation might be a crucial event in the development of metastasis [59]. In addition, researchers found that IL-6/STAT3 signaling pathway could up-regulate the expression of actin-bundling protein (fascin) in gastric cancer cells, which increases proteins that are known to be critical for the execution of metastasis such as MMP-2 and MMP-9 [60]. STAT3 signaling pathway activates metastasis-associated molecules such as MMPs, which might be the mechanism that IL-6/STAT3 uses to promote tumor cell invasion and migration. Therefore, based on our experimental results, we speculated that IL6/STAT3 might play a crucial role in exosomes-treated MCF-7 cells, and the results presented here are consistent with our previous study. Our experimental results suggest a possible mechanism for tumor recurrence and metastasis after chemotherapy.

From our in vivo experiments in nude mice we saw, on one hand, that MCF-7 cells exposed to exosomes from macrophages exposed apoptotic cancer cells or not exposed cells both formed tumors in our xenograft assays. However, tumors from Co-exo exosome treated cells mice grew faster and became larger than those in the other two groups of mice (Figure 7). On the other hand, organotropic metastasis occurs frequently among various cancers [61], which is one of the main causes of death in cancer patients [62]. Breast cancer has been widely reported to most often metastasize to the lungs [63], thus we explored whether MCF-7 cells treated with exosomes could form metastatic lesions in the lungs of nude mice after injection via the tail vein. In our experimental metastatic model, MCF-7 cells from the MCF-7Co-exo group metastasized to the lung more readily than those from the other two groups, with almost no metastasis observed for the MCF-7Mac-exo cells (Figure 7A). Although liver is a common site for metastases for breast cancer [64], no liver metastases were found in our study, which may be a consequence of the pathway, tail vein injection, used to get the exogenous tumor cells into the blood. Additionally, nude mice treated with MCF-7Co-exo cells had a lower body weight (Figure 7C) and had difficulty breathing, phenotypes that are similar to patients with clinically advanced tumors with metastasis. Clinically, breast cancer patients that relapse after chemotherapy often have a poor prognosis [65], which is consistent with our experimental results.

Based on our above findings, we propose the hypothesis presented in Figure 8: Macrophages co-cultured with apoptotic MCF-7 cells (many factors could cause apoptosis of cancer cells, such as treatment, hypoxia, and malnutrition) are modified such that they release altered exosomes to act on naïve MCF-7 cells (MCF-7Co-exo cells). To investigate whether the proliferative and metastatic abilities of the Co-exo exosome treated MCF-7 cells have changed, we conducted both in vitro and in vivo experiments. The in vitro cellular experiments indicated that Co-exo exosome increased IL-6 expression in MCF-7 cells, which activated the STAT3 signaling pathway and promoted the expression of downstream tumor-proliferating (CyclinD1) and metastasis-associated (MMP2/MMP9) genes. To verify the proliferative and metastatic abilities of MCF-7Co-exo cells we examined their tumorigenic ability by subcutaneous injection into nude mice, and found that the size of the subcutaneous tumors generated in the MCF-7Co-exo cell treated mice were significantly larger than those in mice treated with the other two groups of cells. In parallel, we injected MCF-7Co-exo cells into the blood of nude mice, by tail vein injection, and characterized metastases that were found in the lungs of these mice. Thus, we demonstrated the ability of Co-exo exosome to promote tumor cell proliferation and metastasis both in vivo and in vitro. As for what components in the exosomes make them capable of promoting tumor cell proliferation and metastasis, we will conduct additional research to address the specific mechanisms.

Most chemotherapeutic drugs generate reactive oxygen species (ROS) and induce oxidative stress [66, 67]. Here we generated oxidative stress by two different mechanisms, directly using the known oxidant inductor $\mathrm{H}_{2} \mathrm{O}_{2}$ or indirectly using the chemotherapeutic agent cisplatin, which is widely used in the clinic against several solid tumors $[17,68$, 69], and known to induce oxidative stress as part of its secondary effects [70, 71]. High levels of ROS induce cell cycle arrest and apoptosis. In most of our experiments we used $\mathrm{H}_{2} \mathrm{O}_{2}$ because it is an oxidative stress inductor and our doses trigger apoptotic cell death [72, 73]. ROS-modulating drugs are being proposed as therapeutic strategies to selectively target the destruction of cancer cells [74], hence, in the present study, to establish chemotherapy-induced apoptosis in breast cancer cells, $\mathrm{H}_{2} \mathrm{O}_{2}$ was used. Furthermore, to investigate whether other drugs that induce apoptosis yield similar results, we selected 
cisplatin, a widely used oxidative stress-based chemotherapy drug for our experiments. Cisplatin also induced apoptosis of MCF-7 cells (Figure S1A-B), similar to $\mathrm{H}_{2} \mathrm{O}_{2}$. In the future, other types of chemotherapy drugs should be tried in similar studies to acquire more comprehensive results.

The MCF-7 cell line, derived in 1973 from a malignant pleural effusion, is one of the most commonly used culture models for human breast cancer [75]. MCF-7 was chosen due to its proliferative potential and the stage of the disease it represents. MCF-7 are endocrine and chemotherapy responsive (ER+, PR+/-, HER2-) that produce tight cohesive structures with cell-cell adhesions, which have been associated more with cellular proliferation than with cellular metastasis (pre-metastatic stage III cancer). In contrast, MDA-MB-231 (ER-, PR-, HER2-, Triple Negative Breast Cancer, TNBC) cells form loosely cohesive grape-like structures consistent with a more invasive phenotype (metastatic stage IV cancer) [76]. Therefore, utilizing MCF-7 and MDA-MB-231 cells lines allowed us to understand whether similar effects can be seen in different stages of breast cancer. However, only a limited number of in vitro experiments were carried out with the MDA-MB-231 cell line, thus further studies should be conducted, as well as in animals.

In conclusion, our findings suggest that the inhibition of exosome secretion and the STAT3 signaling pathway activation might be promising approach to block the growth and metastasis of breast tumors, thus providing new targets for therapeutic treatment of malignant tumors after clinical chemotherapy.

\section{Supplementary Material}

Supplementary figures.

http://www.jcancer.org/v10p2892s1.pdf

\section{Acknowledgments}

This study was supported by grants from the National Natural Science Foundation of China (NSFC) Grant Numbers 81673459, 81874321; National Key Technologies R\&D Program (Grant Numbers 2012BAK25B01, 2015BAK45B01), and a grant from the National Science Foundation of China - Canadian Institutes of Health Research (NSFC-CIHR) China-Canada Joint Health Research Initiative (Grant Numbers 81061120525 and CCI-109605).

\section{Ethics Committee Approval}

This study was approved by the Ethics Committee of Health Science Center, Peking University, Beijing, China.

\section{Competing Interests}

The authors have declared that no competing interest exists.

\section{References}

1. Ye D, Li Z, Wei C. Genistein inhibits the S-phase kinase-associated protein 2 expression in breast cancer cells. Experimental and therapeutic medicine. 2018; 15: 1069-75.

2. Wu G, Kim D, Kim JN, Park S, Maharjan S, Koh H, et al. A Mucin1 C-terminal Subunit-directed Monoclonal Antibody Targets Overexpressed Mucin1 in Breast Cancer. Theranostics. 2018; 8: 78-91.

3. Kahlert C, Kalluri R. Exosomes in tumor microenvironment influence cancer progression and metastasis. Journal of molecular medicine (Berlin, Germany). 2013; 91: 431-7.

4. Milane L, Singh A, Mattheolabakis G, Suresh M, Amiji MM. Exosome mediated communication within the tumor microenvironment. Journal of controlled release : official journal of the Controlled Release Society. 2015; 219: 278-94.

5. Thery C, Zitvogel L, Amigorena S. Exosomes: composition, biogenesis and function. Nature reviews Immunology. 2002; 2: 569-79.

6. Zhang X, Yuan X, Shi H, Wu L, Qian H, Xu W. Exosomes in cancer: small particle, big player. Journal of hematology \& oncology. 2015; 8: 83.

7. Behbahani GD, Khani S, Hosseini HM, Abbaszadeh-Goudarzi K, Nazeri $\mathrm{S}$. The role of exosomes contents on genetic and epigenetic alterations of recipient cancer cells. Iranian journal of basic medical sciences. 2016; 19: 1031-9.

8. van Niel G, Porto-Carreiro I, Simoes S, Raposo G. Exosomes: a common pathway for a specialized function. Journal of biochemistry. 2006; 140: 13-21.

9. Kourembanas S. Exosomes: vehicles of intercellular signaling, biomarkers, and vectors of cell therapy. Annual review of physiology. 2015; 77: 13-27.

10. Street JM, Barran PE, Mackay CL, Weidt S, Balmforth C, Walsh TS, et al. Identification and proteomic profiling of exosomes in human cerebrospinal fluid. Journal of translational medicine. 2012; 10: 5.

11. Haderk F, Schulz R, Iskar M, Cid LL, Worst T, Willmund KV, et al. Tumor-derived exosomes modulate PD-L1 expression in monocytes. Science immunology. 2017; 2

12. Gordon S, Taylor PR. Monocyte and macrophage heterogeneity. Nature reviews Immunology. 2005; 5: 953-64.

13. King HW, Michael MZ, Gleadle JM. Hypoxic enhancement of exosome release by breast cancer cells. BMC cancer. 2012; 12: 421.

14. Auwerx J. The human leukemia cell line, THP-1: a multifacetted model for the study of monocyte-macrophage differentiation. Experientia. 1991; 47: 22-31

15. Daigneault M, Preston JA, Marriott HM, Whyte MK, Dockrell DH. The identification of markers of macrophage differentiation in PMA-stimulated THP-1 cells and monocyte-derived macrophages. PloS one. 2010; 5: e8668.

16. Zhou N, Zhang Y, Zhang X, Lei Z, Hu R, Li H, et al. Exposure of tumor-associated macrophages to apoptotic MCF-7 cells promotes breast cancer growth and metastasis. International journal of molecular sciences. 2015; 16: 11966-82.

17. Olaussen KA, Dunant A, Fouret P, Brambilla E, Andre F, Haddad V, et al. DNA repair by ERCC1 in non-small-cell lung cancer and cisplatin-based adjuvant chemotherapy. The New England journal of medicine. 2006; 355: 983-91.

18. McDonald MK, Capasso KE, Ajit SK. Purification and microRNA profiling of exosomes derived from blood and culture media. Journal of visualized experiments : JoVE. 2013: e50294.

19. Bai JW, Zhang YQ, Li YC, Zhang GJ. Analysis of Epithelial-Mesenchymal Transition Induced by Overexpression of Twist. Methods in molecular biology (Clifton, NJ). 2017; 1652: 259-74.

20. Peng JM, Chen YH, Hung SW, Chiu CF, Ho MY, Lee YJ, et al. Recombinant viral protein promotes apoptosis and suppresses invasion of ovarian adenocarcinoma cells by targeting alpha5beta1 integrin to down-regulate Akt and MMP-2. British journal of pharmacology. 2012; 165: 479-93

21. Zhao D, Lu X, Wang G, Lan Z, Liao W, Li J, et al. Synthetic essentiality of chromatin remodelling factor CHD1 in PTEN-deficient cancer. Nature. 2017; 542: 484-8.

22. Zhou N, Wang R, Zhang $Y$, Lei Z, Zhang $X, H u$ R, et al. Staurosporine Induced Apoptosis May Activate Cancer Stem-Like Cells (CD44(+)/CD24(-)) in MCF-7 by Upregulating Mucin1 and EpCAM. Journal of Cancer. 2015; 6: 1049-57. 
23. Zheng H, Li Y, Wang Y, Zhao H, Zhang J, Chai H, et al. Downregulation of COX-2 and CYP $4 \mathrm{~A}$ signaling by isoliquiritigenin inhibits human breast cancer metastasis through preventing anoikis resistance, migration and invasion. Toxicology and applied pharmacology. 2014; 280: 10-20.

24. $\mathrm{Xu} \mathrm{W,} \mathrm{Schlagwein} \mathrm{N,} \mathrm{Roos} \mathrm{A,} \mathrm{van} \mathrm{den} \mathrm{Berg} \mathrm{TK,} \mathrm{Daha} \mathrm{MR,} \mathrm{van} \mathrm{Kooten} \mathrm{C.}$ Human peritoneal macrophages show functional characteristics of M-CSF-driven anti-inflammatory type 2 macrophages. European journal of immunology. 2007; 37: 1594-9.

25. Holness CL, Simmons DL. Molecular cloning of CD68, a human macrophage marker related to lysosomal glycoproteins. Blood. 1993; 81: 1607-13.

26. Clawson GA, Matters GL, Xin P, Imamura-Kawasawa $Y, D u ~ Z$, Thiboutot DM, et al. Macrophage-tumor cell fusions from peripheral blood of melanoma patients. PloS one. 2015; 10: e0134320.

27. Biswas SK, Mantovani A. Macrophage plasticity and interaction with lymphocyte subsets: cancer as a paradigm. Nature immunology. 2010; 11: 889-96.

28. Kang Y, Jia P, Zhao H, Hu C, Yang X. MicroRNA-26a overexpression protects RGC-5 cells against $\mathrm{H} 2 \mathrm{O} 2$-induced apoptosis. Biochemical and biophysical research communications. 2015; 460: 164-9.

29. Li J, Huang CY, Zheng RL, Cui KR, Li JF. Hydrogen peroxide induces apoptosis in human hepatoma cells and alters cell redox status. Cell biology international. 2000; 24: 9-23.

30. Liang B, Peng P, Chen S, Li L, Zhang M, Cao D, et al. Characterization and proteomic analysis of ovarian cancer-derived exosomes. Journal of proteomics. 2013; 80: 171-82.

31. Zou Z, Yin Y, Lin J, Hsu LC, Brandon VL, Yang F, et al. Convection-enhanced delivery of sorafenib and suppression of tumor progression in a murine model of brain melanoma through the inhibition of signal transducer and activator of transcription 3. Journal of neurosurgery. 2016; 124: 1310-8.

32. Narayanan PD, Nandabalan SK, Baddireddi LS. Role of STAT3 Phosphorylation in Ethanol-Mediated Proliferation of Breast Cancer Cells. Journal of breast cancer. 2016; 19: 122-32.

33. Ghosh A, Pechota A, Coleman D, Upchurch GR, Jr., Eliason JL. Cigarette smoke-induced MMP2 and MMP9 secretion from aortic vascular smooth cells is mediated via the Jak/Stat pathway. Human pathology. 2015; 46: 284-94.

34. Lei KF, Kao CH, Tsang NM. High throughput and automatic colony formation assay based on impedance measurement technique. Analytical and bioanalytical chemistry. 2017; 409: 3271-7.

35. Jiang $\mathrm{Q}$, Zhang $\mathrm{H}$, Zhang $\mathrm{P}$. ShRNA-mediated gene silencing of MTA1 influenced on protein expression of ER alpha, MMP-9, CyclinD1 and invasiveness, proliferation in breast cancer cell lines MDA-MB-231 and MCF-7 in vitro. Journal of experimental \& clinical cancer research : CR. 2011; 30: 60 .

36. Dinarina A, Santamaria PG, Nebreda AR. Cell cycle regulation of the mammalian CDK activator RINGO/Speedy A. FEBS letters. 2009; 583: 2772-8

37. Wu J, Lv Q, He J, Zhang H, Mei X, Cui K, et al. MicroRNA-188 suppresses G1/S transition by targeting multiple cyclin/CDK complexes. Cell communication and signaling : CCS. 2014; 12: 66.

38. Hung SW, Chiu CF, Chen TA, Chu CL, Huang CC, Shyur LF, et al. Recombinant viral protein VP1 suppresses HER-2 expression and migration/metastasis of breast cancer. Breast cancer research and treatment. 2012; 136: 89-105.

39. Liu B, Cui J, Sun J, Li J, Han X, Guo J, et al. Immunolocalization of MMP9 and MMP2 in osteolytic metastasis originating from MDA-MB-231 human breast cancer cells. Molecular medicine reports. 2016; 14: 1099-106.

40. Manzotti C, Audisio RA, Pratesi G. Importance of orthotopic implantation for human tumors as model systems: relevance to metastasis and invasion. Clinical \& experimental metastasis. 1993; 11: 5-14.

41. Price JE, Zhang RD. Studies of human breast cancer metastasis using nude mice. Cancer metastasis reviews. 1990; 8: 285-97.

42. Huang H, Zheng X, Cai C, Yao Z, Lu S, Meng X, et al. Exosomes derived from breast cancer lung metastasis subpopulations promote tumor self-seeding. Biochemical and biophysical research communications. 2018; 503: 242-8.

43. Chow A, Zhou W, Liu L, Fong MY, Champer J, Van Haute D, et al. Macrophage immunomodulation by breast cancer-derived exosomes requires Toll-like receptor 2-mediated activation of NF-kappaB. Scientific reports. 2014; 4: 5750 .

44. Hu Y, Li D, Wu A, Qiu X, Di W, Huang L, et al. TWEAK-stimulated macrophages inhibit metastasis of epithelial ovarian cancer via exosomal shuttling of microRNA. Cancer letters. 2017; 393: 60-7.
45. Zheng P, Chen L, Yuan X, Luo Q, Liu Y, Xie G, et al. Exosomal transfer of tumor-associated macrophage-derived miR-21 confers cisplatin resistance in gastric cancer cells. Journal of experimental \& clinical cancer research : CR. 2017; 36: 53.

46. Naugler WE, Karin M. The wolf in sheep's clothing: the role of interleukin-6 in immunity, inflammation and cancer. Trends in molecular medicine. 2008; 14: 109-19.

47. Levy DE, Darnell JE, Jr. Stats: transcriptional control and biological impact. Nature reviews Molecular cell biology. 2002; 3: 651-62.

48. Bowman T, Garcia R, Turkson J, Jove R. STATs in oncogenesis. Oncogene. 2000; 19: 2474-88.

49. Bromberg JF, Wrzeszczynska MH, Devgan G, Zhao Y, Pestell RG, Albanese C, et al. Stat3 as an oncogene. Cell. 1999; 98: 295-303.

50. Haura EB, Turkson J, Jove R. Mechanisms of disease: Insights into the emerging role of signal transducers and activators of transcription in cancer. Nature clinical practice Oncology. 2005; 2: 315-24

51. Kishimoto T. Interleukin-6: from basic science to medicine--40 years in immunology. Annual review of immunology. 2005; 23: 1-21.

52. Ishihara K, Hirano T. Molecular basis of the cell specificity of cytokine action. Biochimica et biophysica acta. 2002; 1592: 281-96.

53. $\mathrm{Yu} \mathrm{H}$, Jove R. The STATs of cancer--new molecular targets come of age. Nature reviews Cancer. 2004; 4: 97-105.

54. Scheller J, Ohnesorge N, Rose-John S. Interleukin-6 trans-signalling in chronic inflammation and cancer. Scandinavian journal of immunology. 2006; 63: 321-9.

55. Hirano T, Ishihara K, Hibi M. Roles of STAT3 in mediating the cell growth, differentiation and survival signals relayed through the IL-6 family of cytokine receptors. Oncogene. 2000; 19: 2548-56.

56. Xiong Y, Connolly T, Futcher B, Beach D. Human D-type cyclin. Cell. 1991; 65: 691-9.

57. Egloff AM, Vella LA, Finn OJ. Cyclin B1 and other cyclins as tumor antigens in immunosurveillance and immunotherapy of cancer. Cancer research. 2006; 66: 6-9.

58. McCawley LJ, Matrisian LM. Matrix metalloproteinases: they're not just for matrix anymore! Current opinion in cell biology. 2001; 13: 534-40.

59. Xie TX, Wei D, Liu M, Gao AC, Ali-Osman F, Sawaya R, et al. Stat3 activation regulates the expression of matrix metalloproteinase-2 and tumor invasion and metastasis. Oncogene. 2004; 23: 3550-60.

60. Al-Alwan M, Olabi S, Ghebeh H, Barhoush E, Tulbah A, Al-Tweigeri T, et al. Fascin is a key regulator of breast cancer invasion that acts via the modification of metastasis-associated molecules. PloS one. 2011; 6: e27339.

61. Hoshino A, Costa-Silva B, Shen TL, Rodrigues G, Hashimoto A, Tesic Mark $\mathrm{M}$, et al. Tumour exosome integrins determine organotropic metastasis. Nature. 2015; 527: 329-35.

62. Zhang Z, Sun T, Chen Y, Gong S, Sun X, Zou F, et al. CCL25/CCR9 Signal Promotes Migration and Invasion in Hepatocellular and Breast Cancer Cell Lines. DNA and cell biology. 2016; 35: 348-57.

63. Nguyen DX, Bos PD, Massague J. Metastasis: from dissemination to organ-specific colonization. Nature reviews Cancer. 2009; 9: 274-84.

64. Ma R, Feng Y, Lin S, Chen J, Lin H, Liang X, et al. Mechanisms involved in breast cancer liver metastasis. Journal of translational medicine. 2015; 13: 64 .

65. Selle F, Gligorov J, Richard S, Khalil A, Alexandre I, Avenin D, et al Intensive chemotherapy as salvage treatment for solid tumors: focus on germ cell cancer. Brazilian journal of medical and biological research $=$ Revista brasileira de pesquisas medicas e biologicas. 2015; 48: 13-24

66. Victorino VJ, Pizzatti L, Michelletti P, Panis C. Oxidative stress, redox signaling and cancer chemoresistance: putting together the pieces of the puzzle. Current medicinal chemistry. 2014; 21: 3211-26.

67. Mahalingaiah PK, Singh KP. Chronic oxidative stress increases growth and tumorigenic potential of MCF-7 breast cancer cells. PloS one. 2014; 9: e87371

68. Nardon C, Boscutti G, Fregona D. Beyond platinums: gold complexes as anticancer agents. Anticancer research. 2014; 34: 487-92.

69. Shaili E. Platinum anticancer drugs and photochemotherapeutic agents: recent advances and future developments. Science progress. 2014; 97: $20-40$.

70. Gomez-Sierra T, Molina-Jijon E, Tapia E, Hernandez-Pando R, Garcia-Nino WR, Maldonado PD, et al. S-allylcysteine prevents cisplatin-induced nephrotoxicity and oxidative stress. The Journal of pharmacy and pharmacology. 2014; 66: 1271-81.

71. Palipoch S, Punsawad C, Koomhin P, Suwannalert P. Hepatoprotective effect of curcumin and alpha-tocopherol against cisplatin-induced oxidative stress. BMC complementary and alternative medicine. 2014; 14: 111

72. Katsube $\mathrm{T}$, Mori $\mathrm{M}$, Tsuji $\mathrm{H}$, Shiomi $\mathrm{T}$, Wang $\mathrm{B}$, Liu $\mathrm{Q}$ et al. Most hydrogen peroxide-induced histone $\mathrm{H} 2 \mathrm{AX}$ phosphorylation is mediated 
by ATR and is not dependent on DNA double-strand breaks. Journal of biochemistry. 2014; 156: 85-95.

73. Bauer G. Targeting extracellular ROS signaling of tumor cells. Anticancer research. 2014; 34: 1467-82.

74. Badmus JA, Ekpo OE, Hussein AA, Meyer M, Hiss DC. Antiproliferative and Apoptosis Induction Potential of the Methanolic Leaf Extract of Holarrhena floribunda (G. Don). Evidence-based complementary and alternative medicine : eCAM. 2015; 2015: 756482.

75. Leung E, Kim JE, Askarian-Amiri M, Finlay GJ, Baguley BC. Evidence for the existence of triple-negative variants in the MCF-7 breast cancer cell population. BioMed research international. 2014; 2014: 836769.

76. Trejo-Vargas A, Hernandez-Mercado E, Ordonez-Razo RM, Lazzarini R, Arenas-Aranda DJ, Gutierrez-Ruiz MC, et al. Bik subcellular localization in response to oxidative stress induced by chemotherapy, in Two different breast cancer cell lines and a Non-tumorigenic epithelial cell line. Journal of applied toxicology : JAT. 2015; 35: 1262-70. 